\title{
BIOCHEMICAL PROFILE AND VARIOUS TREATMENT MODALITIES OF PATIENTS WITH NON-ALCOHOLIC STEATOHEPATITIS (NASH)
}

\author{
Vinod Kumar1, Ritu Bhagat ${ }^{2}$
}

${ }_{1} M D$, Department of Medicine, GMC, Jammu, Jammu and Kashmir, India.

${ }_{2}^{2} \mathrm{MD}$, Department of Pathology, GMC, Jammu, Jammu and Kashmir, India.

\section{BACKGROUND}

ABSTRACT

Non-alcoholic fatty liver disease (NAFLD) is an increasingly recognized condition that may progress to end stage liver disease. Although non-alcoholic steatohepatitis (NASH) was considered relatively uncommon prior to middle of last decade, over the past few years there has been an explosion of studies on various aspects of NASH with one study reporting that after hepatitis C, NASH was the most common diagnosis in patients presenting largely with persistent abnormalities of liver function tests. We wanted to study the biochemical profile and various treatment modalities in patients of non-alcoholic steatohepatitis (NASH).

\section{METHODS}

The present study was carried out on 60 patients of NASH over a period of one year at Pathology Department of GMC, Jammu, which is a tertiary care centre. All patients with NASH were screened for various risk factors associated with NASH. Detailed history was taken, and thorough clinical examination was done. Required investigations were done such as Hb, TLC, DLC, blood sugar, renal function tests, complete liver tests, serum lipid profile, viral markers (HBsAg and Anti-HCV) and ANA. Ultrasound abdomen for hepatobiliary system was done to diagnose the patients of NASH.

\section{RESULTS}

Out of 60 patients, 28 (46.66\%) were males and 32 (53.32\%) were females. 85\% of the patients were in the age group of 31-70 years. Out of 60 patients only 16 patients followed regularly and remained under close supervision.

\section{CONCLUSIONS}

In the present study, it was found that obesity was present in $46.6 \%$ cases whereas $50 \%$ patients were hyperlipidaemic. $38 \%$ patients were suffering from diabetes. It was found that there was marked symptomatic and biochemical improvement in those who were on strict dietary control and on regular follow up.

HOW TO CITE THIS ARTICLE: Kumar V, Bhagat R. Biochemical profile and various treatment modalities of patients with nonalcoholic steatohepatitis (NASH). J. Evolution Med. Dent. Sci. 2019;8(17):1405-1407, DOI: 10.14260/jemds/2019/312

\section{BACKGROUND}

Non-alcoholic fatty liver disease refers to wide spectrum of liver damage ranging from simple steatosis to steatohepatitis, advanced fibrosis and cirrhosis. Steatohepatitis represents only a stage within the spectrum of non-alcoholic fatty liver disease.[1] Ludwig et al introduced term non-alcoholic steatohepatitis to describe liver disease that is histologically indistinguishable from alcoholic hepatitis but occurs in persons who do not consume excess alcohol.[2] NAFLD is defined as fat accumulation in liver exceeding $5 \%$ to $10 \%$ by weight. Inherent to defining NAFLD and NASH is threshold at which steatohepatitis become alcohol related. Many centers accepts upper limit of 20-40 gm/day in men and $20 \mathrm{gm} /$ day in women.[3] NAFLD is found in $70 \%$ of obese and $35 \%$ of lean patients. NASH is found in $18.5 \%$ of obese and $2.7 \%$ of lean patients. There is even distribution of NASH among men and women.

'Financial or Other Competing Interest': None.

Submission 13-03-2019, Peer Review 16-04-2019,

Acceptance 23-04-2019, Published 29-04-2019.

Corresponding Author:

Dr. Ritu Bhagat,

D/o. K. C. Bhagat,

209 Colonel Colony,

Talab Tillo-Bohri,

Jammu-180001

Jammu and Kashmir, India.

E-mail:drvkadin76@gmail.com

DOI: $10.14260 /$ jemds $/ 2019 / 312$

\section{METHODS}

The present work is a hospital based cross-sectional study that included 60 patients of NASH registered with GMC, Jammu for a period of one year. All patients with NASH were screened for various risk factors associated with NASH. Detailed history was taken, and thorough clinical and biochemical profile was done. Necessary investigations like Hb, TLC, DLC, blood sugar, renal function tests, complete liver tests, serum lipid profile, viral markers (HBsAg and Anti HCV) and ANA were done. Ultrasound abdomen for hepatobiliary system was done to diagnose the patients of NASH. Got approval from IEC and consent was taken from all patients.

\section{Inclusion Criteria}

1. Ultrasonographically proven fatty liver.

2. Deranged liver function tests.

3. No significant alcohol intake i.e. $<20 \mathrm{gm} /$ day.

4. Absence of other relevant liver disease.

\section{Exclusion Criteria}

1. Daily alcohol intake i.e. $>20 \mathrm{gm} /$ day.

2. Use of amiodarone, steroids, tamoxifen, methotrexate or high dose oestrogen.

3. Jejunal bypass or extensive small bowel resection.

4. Other known liver disease.

5. Malignancy. 


\section{Statistical Methods}

The statistical package for social science $\{$ SPSS $\}$ version 20 will be used for data analysis. Mean, median, and SD are used to describe quantitative data. Qualitative data are summarized using frequency and percentage.

\section{RESULTS}

\begin{tabular}{|c|c|c|c|c|c|c|}
\hline \multirow{2}{*}{$\begin{array}{c}\text { Age Group } \\
\text { in Years }\end{array}$} & \multicolumn{2}{|c|}{ Males } & \multicolumn{2}{c|}{ Females } & \multicolumn{2}{c|}{ Total } \\
\cline { 2 - 7 } & No. & $\%$ & No. & $\%$ & No. & $\%$ \\
\hline $10-30$ & 5 & 8.33 & 2 & 3.33 & 7 & 11.66 \\
\hline $31-50$ & 17 & 28.33 & 16 & 26.66 & 33 & 55.0 \\
\hline $51-70$ & 6 & 10.0 & 12 & 20.0 & 18 & 30.0 \\
\hline$>70$ & 0 & 0.0 & 2 & 3.33 & 2 & 3.33 \\
\hline Total & $\mathbf{2 8}$ & $\mathbf{4 6 . 6 6}$ & $\mathbf{3 2}$ & $\mathbf{5 3 . 3 2}$ & $\mathbf{6 0}$ & $\mathbf{1 0 0}$ \\
\hline \multicolumn{6}{|c|}{ Table 1. Age and Sex Distribution } \\
\hline
\end{tabular}

Out of 60 patients, 28 were males and 32 were females. Majority of patients were in the group of 31-50 years (55\%) followed by that in $51-70$ years (30\%). Thus, $85 \%$ of the patients were in the age of 31-70 years.

\begin{tabular}{|c|c|c|}
\hline \multirow{2}{*}{ Body Mass Index } & \multicolumn{2}{|c|}{ No. of Patients } \\
\cline { 2 - 3 } & Males & Female \\
\hline $18.5-24.9$ & $4(14.28 \%)$ & $5(15.62 \%)$ \\
\hline $25-29.9$ & $8(28.56 \%)$ & $15(46.87 \%)$ \\
\hline $30-34.9$ & $14(50.02 \%)$ & $12(37.51 \%)$ \\
\hline $35-39.9$ & $2(7.14 \%)$ & 0 \\
\hline Total & $\mathbf{2 8 ( 1 0 0 \% )}$ & $\mathbf{3 2 ~ ( 1 0 0 \% )}$ \\
\hline \multicolumn{2}{|c|}{ Table 2. Specific Classification of BMI } \\
\hline
\end{tabular}

\begin{tabular}{|c|c|c|}
\hline \multirow{2}{*}{ Tests } & \multicolumn{2}{|c|}{ No. of Patients } \\
\hline & Male & Female \\
\hline Increased Serum Bilirubin & 13 & 14 \\
\hline Increased AST & 24 & 27 \\
\hline Increased ALT & 28 & 29 \\
\hline AST: ALT > 1 & 2 & 3 \\
\hline Increased Alk. $\mathrm{PO}_{4}$ & 6 & 4 \\
\hline Total * & 73 & 77 \\
\hline Table 3. Live & ion ? & \\
\hline
\end{tabular}

\begin{tabular}{|c|c|c|}
\hline \multirow{2}{*}{ Fasting Blood Sugar } & \multicolumn{2}{|c|}{ No. of Patients } \\
\cline { 2 - 3 } & Male & Female \\
\hline$<100$ & $9(32.14 \%)$ & $14(43.75 \%)$ \\
\hline $100-125$ & $9(32.14 \%)$ & $5(15.62 \%)$ \\
\hline$\geq 126$ & $10(35.72 \%)$ & $13(40.63 \%)$ \\
\hline Total & $28(100 \%)$ & $32(100 \%)$ \\
\hline \multicolumn{3}{|c|}{ Table 4. Fasting Blood Sugar } \\
\hline
\end{tabular}

\begin{tabular}{|c|c|c|}
\hline \multirow{2}{*}{ Risk Factors } & Male & Female \\
\cline { 2 - 3 } & 16 & 12 \\
\hline Obesity & 17 & 13 \\
\hline Hyperlipidaemia & 10 & 13 \\
\hline Diabetes Mellitus & 43 & 38 \\
\hline \multicolumn{2}{|c|}{ Total* } & Table 5. Associated Risk Factors \\
\hline \multicolumn{2}{|c|}{. } \\
*The numbers don't add up to 60 since more than one \\
sign/symptom was present in single patient. \\
In the present study it was found that obesity, \\
hyperlipidaemia and diabetes mellitus were significantly \\
associated with the NASH (n=60) \\
\hline
\end{tabular}

\begin{tabular}{|c|c|c|}
\hline Variables & Mean & Range \\
\hline Age (y) & 44 & $22-75$ \\
\hline Sex Female (\%) & $32 \%$ & \\
\hline Anthropometric Data & & \\
\hline$\bullet \quad$ Obesity (\%) & $46 \%$ & \\
\hline$\bullet \quad$ Overweight (\%) & $39 \%$ & \\
\hline$\bullet \quad$ Lean (\%) & $15 \%$ & \\
\hline$\bullet \quad$ Body weight & $75.3 \mathrm{~kg}$ & $56-110 \mathrm{~kg}$ \\
\hline$\bullet \quad$ BMI & 29.18 & $20.0-39.9$ \\
\hline Waist Circumference & & \\
\hline$\bullet \quad$ Men > 102 cm & $10 / 28(35 \%)$ & \\
\hline$\bullet \quad$ Women $>88 \mathrm{~cm}$ & $25 / 32(78 \%)$ & \\
\hline S. Bilirubin & 1.4 & $0.5-8.2$ \\
\hline AST & 73.21 & $28-285$ \\
\hline ALT & 102.35 & $33-240$ \\
\hline Alk. PO4. & 97.75 & $59-176$ \\
\hline Glucose Tolerance & & \\
\hline$\bullet \quad$ Diabetes Mellitus & $23 / 60(38.3 \%)$ & \\
\hline$\bullet \quad$ Impaired Glucose & $14 / 60(23.3 \%)$ & \\
\hline Fasting & $30 / 60(50 \%)$ & \\
\hline Hyperlipidaemia & Table 6 \\
\hline \multicolumn{2}{|c|}{} \\
\hline
\end{tabular}

\begin{tabular}{|c|c|c|c|c|c|c|}
\hline & $=$ & 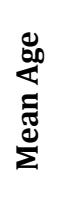 & 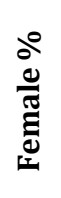 & 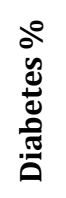 & $\begin{array}{l}0 \\
\stackrel{0}{0} \\
\stackrel{0}{0} \\
0 \\
0\end{array}$ & 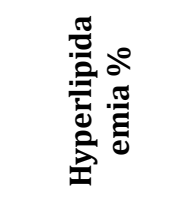 \\
\hline Ludwig & 20 & 54 & 65 & 50 & 90 & 67 \\
\hline Diehl & 39 & 52 & 81 & 55 & 71 & 20 \\
\hline Lee & 49 & 53 & 78 & 51 & 69 & Not Reported \\
\hline Powell & 42 & 49 & 83 & 36 & 95 & 81 \\
\hline Bacon & 33 & 47 & 42 & 21 & 39 & 21 \\
\hline Matteoni & 132 & 53 & 53 & 33 & 70 & 92 \\
\hline Angulo & 144 & 51 & 67 & 28 & 60 & 27 \\
\hline Our Study & 60 & 44 & 53 & 38 & 46 & 43 \\
\hline \multicolumn{7}{|c|}{ Table 7} \\
\hline
\end{tabular}

\section{Various Treatment Modalities}

16 patients followed regularly and remained under close supervision and were evaluated after 6 months of treatment. They were asked to cut down the intake of fats and avoid red meat. They were asked for daily brisk walking for one hour each in the morning and evening. Out of 60, 56 patients were prescribed vitamin E $800 \mathrm{IU} /$ day and 4 patients were put on metformin $500 \mathrm{mg} /$ day. After six months, they were reevaluated, and it was found that their raised enzymes reduced markedly.

\section{DISCUSSION}

Present study was undertaken in 60 patients to assess the biochemical profile and various treatment modalities of patients with non-alcoholic steatohepatitis. Out of which 28 (46.66\%) were males and 32 (53.32\%) were females. Maximum patients were in the age group of 31-50 years (55\%) followed by that in $51-70$ years (30\%). Thus $85 \%$ of the patients in the age group of 31-70 years.

In our study $46.6 \%(28 / 60)$ patients were found to be obese and $38.3 \%(23 / 60)$ were found to be overweight. Thus, total of $84.9 \%(51 / 60)$ patients had BMI $>25.9$ (15\%) patients were found to have BMI $<25$. Ludwig et al in his study found 
that $90 \%$ of patients with NASH were obese ${ }^{[4]}$ whereas Lee in demonstrated in his study that $69 \%$ patients with NASH were obese. ${ }^{[5]}$ Bacon et al in their study that $39 \%$ patients of NASH were obese.[6] Angulo et al found in their study that $60 \%$ of patients with NASH were obese.[7]

In our study $50 \%(30 / 60)$ patients were found to be hyperlipidaemic. Out of 30, 16 patients had raised VLDL, 9 patients had raised triglycerides and 5 patients had raised both VLDL and triglycerides. Ludwig et al in their study found that $67 \%$ of patients of NASH were hyperlipidaemic.[4] Diehl et al in their study found that $20 \%$ of patients of NASH were hyperlipidaemic whereas Bacon et al in their study found $21 \%$ of patients of NASH to be hyperlipidaemic.[6] Angulo et al demonstrated that $27 \%$ patients of NASH were hyperlipidaemic.[7]

In our study of $38.3 \%(23 / 60)$ patients were found to be diabetic. Ludwig et al found $50 \%$ of patients of NASH to be diabetic [4] whereas Diehl et al demonstrated in their study that $55 \%$ patients of NASH were diabetic. In the study conducted by Powell et al, $36 \%$ of patients of NASH were found to be diabetic.[8] Bacon et al demonstrated that $21 \%$ of patients were diabetic.[6] Angulo et al found $28 \%$ of patients of NASH to be diabetic.[7]

Out of 60 patients only 16 patients followed regularly and remained under close supervision, they were asked to cut down the intake of fats and avoid red meat. They were asked for daily brisk walking for one hour each in the morning and evening. 56 patients were put on vitamin E $800 \mathrm{IU} /$ day. 4 patients were put on metformin $500 \mathrm{mg} /$ day. But the patients put on metformin left the study on their own because they were told by someone that metformin is used to decrease blood sugar. All patients were asked for regular follow up but only 16 patients completed study. They were evaluated at the end of six months and it was found that there was marked symptomatic and biochemical improvement.

\section{CONCLUSION}

Obesity was present in $46.6 \%$ cases whereas $50 \%$ patients were hyperlipidaemic. 38\% patients were suffering from diabetes. It was found that there was marked symptomatic and biochemical improvement in those who were on strict dietary control and on regular follow up.

\section{REFERENCES}

[1] Angulo P. Non-alcoholic fatty liver disease. NEJM 2002;346(16):1221-31.

[2] Caldwell SH, Oelsner DH, Lezzoni JC, et al. Cryptogenic cirrhosis: clinical characterization and risk factors for underlying disease. Hepatology 1999;29(3):664-9.

[3] Neuschwander-Tetri BA, Caldwell SH. Non-alcoholic steatohepatitis: summary of an AASLD sigle topic conference. Hepatology 2003;37(5):1202-19.

[4] Ludwig J, Viggiano TR, McGill DB, et al. Non-alcoholic steatohepatitis: mayo clinic experience with a hitherto unnamed disease. Mayo Clin Proc 1980;55(7):434-8.

[5] Lee RG. Nonalcoholic steatohepatitis: a study of 49 patients. Hum Pathol 1989;20(6):594-8.

[6] Bacon BR, Faravash MJ, Janney CG, et al. Non-alcoholic steatohepatitis: an expanded clinical entity. Gastroenterology 1994;107(4):1103-09.

[7] Angulo P, Keach JC, Batts KP, et al. Independent predictors of liver fibrosis in patients with nonalcoholic $\quad$ steatohepatitis. Hepatology 1999;30(6):1356-62.

[8] Powell EE, Cooksley WGE, Hanson R, et al. The natural history of non-alcoholic steatohepatitis: a follow up study of forty two patients for up to 21 years. Hepatology 1990;11(1):74-80. 